\title{
Reference Member State
}

National Cancer Institute

\section{Source}

National Cancer Institute. Reference Member State. NCI Thesaurus. Code C156641.

A European Economic Area country with marketing authorization for a medicinal product that evaluates the marketing authorization application dossier and prepares the assessment report on behalf of another European Economic Area country that is seeking to obtain marketing authorization for the same product through Mutual Recog nition or Decentralized procedures. 